\title{
Health indexes for power transformers: A case study
}

Félix Ortiz, Inmaculada Fernández, Alfredo Ortiz, Carlos J. Renedo, Fernando Delgado, Cristina Fernández

Electrical and Energy Engineering Department, School of Industrial and Telecommunications

Engineering, University of Cantabria, Avda. Los Castros, s/n. Santander, Spain

Email (ortizfa@unican.es)

\section{Keywords}

Power transformer, aging, insulation system, dissolved gas analysis, furans, health index.

\section{Summary}

It seems essential that a health index for a power transformer should take into account the age of the transformer and its loading in service.

\section{Introduction}

Proper operation of power transformers is critical to ensuring transmission and distribution of electrical power. Most transformers have an electrical insulation system based on oil and paper. The state of the insulation system is the major factor influencing the state of the transformer.

During service the dielectric materials within the transformer deteriorate, and small concentrations of impurities such as water, carbon monoxide, carbon dioxide and furan compounds accumulate in the oil. Since it is easy to obtain oil samples from power transformers, the information most commonly collected by transformer fleet managers relates to the physical and dielectric properties of the oil. These properties include dielectric strength, dissipation factor, color and interfacial tension, and concentrations of dissolved gases, furans, acids and moisture.

Using these properties it is possible to determine whether a transformer has developed certain specific faults, e.g., partial discharges, arcing, sparking, overheating, etc. On the other hand, various health indexes have been proposed in order to characterize the general condition of a transformer [1] - [3]. The factors taken into account in these indexes by these indicators vary, and are given different statistical weightings depending on their influence on the general condition of the transformer.

In this article we evaluate the condition of a fleet of operating power transformers, using two recently-proposed health indexes, and compare the results.

\section{Transformers fleet}

The fleet consisted of 52 industrial transformers whose insulation systems consisted of Kraft paper and mineral oil. The power range of the transformers was 1.6 - 135 MVA, and the voltage range was 12 - $220 \mathrm{kV}$. The most common cooling systems were ONAN, ONAF and OFWF. They were divided into five main groups, with average years-in-service of $10,20,30,40$ and 50 years. The transformers came from three different manufacturers.

\section{Experimental}


The physical properties of the oil in the transformers were measured periodically, in accordance with the following standards: water content (IEC 60814), dielectric strength (IEC 60156), color (ASTM D1500), interfacial tension (ASTM D971-12) acidity (ASTM D-664) and dielectric loss (IEC 61620). The concentrations of hydrogen $\left(\mathrm{H}_{2}\right)$, carbon monoxide $(\mathrm{CO})$, carbon dioxide $\left(\mathrm{CO}_{2}\right)$, methane $\left(\mathrm{CH}_{4}\right)$, ethane $\left(\mathrm{C}_{2} \mathrm{H}_{6}\right)$, ethylene $\left(\mathrm{C}_{2} \mathrm{H}_{4}\right)$ and acetylene $\left(\mathrm{C}_{2} \mathrm{H}_{2}\right)$ accumulating in the oil were also measured periodically, in accordance with IEC 60567. (The interpretation of these concentrations and the ratios of the concentrations of certain pairs of gases are given in IEC 60599). The concentrations of furan compounds in the oil were also measured periodically, in accordance with IEC 61198.

\section{Health index analysis}

As stated above, a single health index can be used to characterize the overall condition of a power transformer. Many health indexes have been proposed by different authors [1]-[8]. Some of these indexes use subjective parameters, e.g., tank corrosion, cooling equipment, connectors, and protection equipment, which are difficult to evaluate. However, two health indexes based on the values of clearly defined quantities, routinely measured by power transformer owners, have recently been proposed [7], [8]. The main difference between them is that only one [8] considers the real age and the load regime of the transformer. The aim of the present work was to determine which of the two indexes studied provided the more accurate measure of transformer overall condition.

\subsection{Health index 1 [7]}

The first health index, $I_{1}$, takes into account three health subindexes corresponding to oil quality [7]. These are:

(1) $I_{1}(1)$, based on dielectric strength, dissipation factor, acidity, moisture, color and interfacial tension of the oil.

(2) $I_{1}(2)$, based on dissolved gas content of the oil.

(3) $I_{1}(3)$, based on furans content of the oil.

Subindex $I_{1}(1)$ can have values $0,1,2,3$ and 4 , depending on the condition of the oil, as shown in Table 1 . The corresponding data for subindex $I_{1}(2)$ are identical to those shown in Table 1.

Table 1. Subindex $I_{1}(1)$ of oil condition (based on [7]).

\begin{tabular}{|c|c|c|}
\hline State & Range & $\mathbf{I}_{\mathbf{1}}(\mathbf{1})$ \\
\hline Very good & $\mathrm{HI}_{1}(1)<1.2$ & 4 \\
\hline Good & $1.2 \leq \mathrm{HI}_{1}(1)<1.5$ & 3 \\
\hline Regular & $1.5 \leq \mathrm{HI}_{1}(1)<2$ & 2 \\
\hline Bad & $2 \leq \mathrm{HI}_{1}(1)<3$ & 1 \\
\hline Very bad & $\mathrm{HI}_{1}(1) \geq 3$ & 0 \\
\hline
\end{tabular}

The factor $\mathrm{HI}_{1}(1)$ in Table 1 is defined as:

$$
H I_{1}(1)=\frac{\sum_{j=1}^{6} s_{j} \cdot w_{j}}{\sum_{j=1}^{6} w_{j}}
$$

where the summation is over the six physical and dielectric properties of the oil. The scores $\mathrm{s}_{\mathrm{j}}$ and weights $\mathrm{w}_{\mathrm{j}}$ are given in Table 2. 
Table 2. Scores $\left(\mathrm{s}_{\mathrm{j}}\right)$ and weights $\left(\mathrm{w}_{\mathrm{j}}\right)$ for the six physical and dielectric properties of the oil (based on [7]).

\begin{tabular}{|c|c|c|c|c|c|}
\hline & $\mathrm{U} \leq 69 \mathrm{kV}$ & $69 \mathrm{kV}<\mathrm{U}<230 \mathrm{kV}$ & $U \geq 230 \mathrm{kV}$ & $\mathbf{s}_{\mathbf{j}}$ & $\mathbf{w}_{\mathbf{j}}$ \\
\hline \multirow{4}{*}{$\begin{array}{c}\text { Dielectric } \\
\text { strength }[k V]^{*}\end{array}$} & $\geq 45$ & $\geq 52$ & $\geq 60$ & 1 & \multirow{4}{*}{3} \\
\hline & $35-45$ & $47-52$ & $50-60$ & 2 & \\
\hline & $30-35$ & $35-47$ & $40-50$ & 3 & \\
\hline & $\leq 30$ & $\leq 35$ & $\leq 40$ & 4 & \\
\hline \multirow{4}{*}{$\begin{array}{c}\text { Interfacial } \\
\text { tension } \\
{[\mathrm{mN} / \mathrm{m}]}\end{array}$} & $\geq 25$ & $\geq 30$ & $\geq 32$ & 1 & \multirow{4}{*}{2} \\
\hline & $20-25$ & $23-30$ & $25-32$ & 2 & \\
\hline & $15-20$ & $18-23$ & $20-25$ & 3 & \\
\hline & $\leq 15$ & $\leq 18$ & $\leq 20$ & 4 & \\
\hline \multirow{4}{*}{$\begin{array}{c}\text { Acidity } \\
\text { [mg KOH/g] }\end{array}$} & $\leq 0.05$ & $\leq 0.04$ & $\leq 0.03$ & 1 & \multirow{4}{*}{1} \\
\hline & $0.05-0.1$ & $0.04-0.1$ & $0.03-0.07$ & 2 & \\
\hline & $0.1-0.2$ & $0.1-0.15$ & $0.07-0.1$ & 3 & \\
\hline & $\geq 0.2$ & $\geq 0.15$ & $\geq 0.1$ & 4 & \\
\hline \multirow{4}{*}{$\begin{array}{l}\text { Moisture } \\
\text { [ppm] }\end{array}$} & $\leq 30$ & $\leq 20$ & $\leq 15$ & 1 & \multirow{4}{*}{4} \\
\hline & $30-35$ & $20-25$ & $15-20$ & 2 & \\
\hline & $35-40$ & $25-30$ & $20-25$ & 3 & \\
\hline & $\geq 40$ & $\geq 30$ & $\geq 25$ & 4 & \\
\hline \multirow{4}{*}{$\begin{array}{c}\text { Color scale } \\
\text { [ASTM D-1500] }\end{array}$} & \multicolumn{3}{|c|}{$\leq 1.5$} & 1 & \multirow{4}{*}{2} \\
\hline & & $1.5-2.0$ & & 2 & \\
\hline & & $2.0-2.5$ & & 3 & \\
\hline & & $\geq 2.5$ & & 4 & \\
\hline \multirow{4}{*}{$\begin{array}{l}\text { Dissipation } \\
\text { factor }\end{array}$} & & $\leq 0.1$ & & 1 & \multirow{4}{*}{3} \\
\hline & & $0.1-0.5$ & & 2 & \\
\hline & & $0.5-1$ & & 3 & \\
\hline & & $\geq 1$ & & 4 & \\
\hline
\end{tabular}

${ }^{*}$ Assuming an electrode separation of $2.5 \mathrm{~mm}$ (IEC 60156)

The factor $\mathrm{HI}_{1}(2)$ is defined as:

$$
H I_{1}(2)=\frac{\sum_{j=1}^{7} s_{j} \cdot w_{j}}{\sum_{j=1}^{7} w_{j}}
$$

where the summation is over the seven dissolved gases. The scores $s_{j}$ and weights $\mathrm{w}_{\mathrm{j}}$ are given in Table 3.

Table 3. Scores and weights for the dissolved gases in the oil (based on [7]).

\begin{tabular}{|c|c|c|c|c|c|c|c|}
\hline \multirow{2}{*}{$\begin{array}{c}\text { Gas } \\
\text { (ppm) }\end{array}$} & \multicolumn{6}{|c|}{ Score $\left(s_{j}\right)$} & \multirow[t]{2}{*}{$\mathbf{w}_{\mathbf{j}}$} \\
\hline & 1 & 2 & 3 & 4 & 5 & 6 & \\
\hline $\mathrm{H}_{2}$ & $\leq 100$ & $100-200$ & $200-300$ & $300-500$ & $500-700$ & $>700$ & 2 \\
\hline $\mathrm{CH}_{4}$ & $\leq 75$ & $75-125$ & $125-200$ & $200-400$ & $400-600$ & $>600$ & 3 \\
\hline $\mathrm{C}_{2} \mathrm{H}_{6}$ & $\leq 65$ & $65-80$ & $80-100$ & $100-120$ & $120-150$ & $>150$ & 3 \\
\hline $\mathrm{C}_{2} \mathrm{H}_{4}$ & $\leq 50$ & $50-80$ & $80-100$ & $100-150$ & $150-200$ & $>200$ & 3 \\
\hline $\mathrm{C}_{2} \mathrm{H}_{2}$ & $\leq 3$ & $3-7$ & $7-35$ & $35-50$ & $50-80$ & $>80$ & 5 \\
\hline $\mathrm{CO}$ & $\leq 350$ & $350-700$ & $700-900$ & $900-1100$ & $1100-1400$ & $>1400$ & 1 \\
\hline $\mathrm{CO}_{2}$ & $\leq 2500$ & $2500-3000$ & $3000-4000$ & $4000-5000$ & $5000-7000$ & $>7000$ & 1 \\
\hline
\end{tabular}

Subindex $I_{1}(3)$ can take five different values, corresponding to the furan concentration in the oil, as shown in Table 4.

Table 4. Values of the subindex $l_{1}(3)$ as a function of the furan concentration in the oil (based on [7]).

\begin{tabular}{|c|c|}
\hline 2FAL (ppb) & $\mathbf{I}_{\mathbf{1}}(\mathbf{3})$ \\
\hline $0-100$ & 4 \\
\hline $100-250$ & 3 \\
\hline $250-500$ & 2 \\
\hline $500-1000$ & 1 \\
\hline$>1000$ & 0 \\
\hline
\end{tabular}


The overall health index $I_{1}$ is given by

$$
I_{1}=\frac{\sum_{i=1}^{3} k_{i} \cdot I_{1}(i)}{4 \cdot \sum_{i=1}^{3} k_{i}}
$$

where the weights $\mathrm{k}_{1}$ (physical and dielectric properties), $\mathrm{k}_{2}$ (dissolved gases content) and $\mathrm{k}_{3}$ (furan content) are 8,10 and 5 respectively. $\mathrm{l}_{1}$ lies in the range $0-1.00$. The overall condition of the transformer, based on the value of $\mathrm{I}_{1}$, is listed in Table 5.

Table 5. Transformer condition as a function of health index $l_{1}$ (based on [7]).

\begin{tabular}{|c|c|}
\hline $\mathbf{I}_{\mathbf{1}}$ & Condition \\
\hline $0.85-1.00$ & Very good \\
\hline $0.70-0.85$ & Good \\
\hline $0.50-0.70$ & Fair \\
\hline $0.30-0.50$ & Poor \\
\hline $0.00-0.30$ & Very poor \\
\hline
\end{tabular}

\section{2.- Health index 2 [8]}

The second index $\mathrm{I}_{2}$ consists of four subindexes.

The first subindex $I_{2}(1)$ is concerned with the state of the insulating paper in the transformer, and consists of two factors. The first of these, $\mathrm{HI}_{2}(\mathrm{C}, \mathrm{O})$, is concerned with the concentrations of $\mathrm{CO}$ and $\mathrm{CO}_{2}$ dissolved in the transformer oil, and the second, $\mathrm{HI}_{2}$ (fur), is concerned with the concentrations of furans in the oil. $\mathrm{HI}_{2}(\mathrm{C}, \mathrm{O})$ is one-third of the sum $F_{1}+F_{2}+F_{3}$, where the values of $F_{1}, F_{2}$ and $F_{3}$ are expressed in the form $a x+b$; $a$ and $b$ are constants and $x$ is the concentration of the relevant gas, as shown in Table 6.

Table 6. Values of $F_{1}, F_{2}$ and $F_{3}$ (based on [8]).

\begin{tabular}{|c|c|c|c|c|}
\hline Gas & $\begin{array}{l}\text { Concentration } \\
\text { range } x(\mu L / L)\end{array}$ & a & b & $\mathbf{F}$ \\
\hline \multirow{5}{*}{$\mathrm{CO}$} & $0-300$ & 0.0067 & 0 & \multirow{4}{*}{$F_{1}=a x+b$} \\
\hline & $300-900$ & 0.0017 & 1.5 & \\
\hline & $900-1000$ & 0.020 & -4.97 & \\
\hline & $1000-1400$ & 0.0125 & -7.50 & \\
\hline & $>1400$ & - & - & $F_{1}=10$ \\
\hline \multirow{6}{*}{$\mathrm{CO}_{2}$} & $0-2400$ & 0.0008 & 0 & \multirow{5}{*}{$F_{2}=a x+b$} \\
\hline & $2400-3000$ & 0.0033 & -6.0 & \\
\hline & $3000-5000$ & 0.0005 & 2.4 & \\
\hline & $5000-10000$ & 0.0008 & 0.9 & \\
\hline & $10000-13000$ & 0.0003 & 5.9 & \\
\hline & $>13000$ & - & - & $F_{2}=10$ \\
\hline \multirow{5}{*}{$\mathrm{CO}+\mathrm{CO}_{2}$} & $0-3000$ & 0.00067 & 0 & \multirow{4}{*}{$F_{3}=a x+b$} \\
\hline & $3000-10000$ & 0.00014 & 1.59 & \\
\hline & $10000-170000$ & 0.000033 & 2.66 & \\
\hline & $170000-350000$ & $9.44 \cdot 10^{-6}$ & 6.65 & \\
\hline & $>350000$ & - & - & $F_{3}=10$ \\
\hline
\end{tabular}

$\mathrm{HI}_{2}$ (fur) is given by

$$
\mathrm{HI}_{2}(\text { fur })=3.344 \cdot\left(C_{\text {fur }}\right)^{0.413}
$$

where $\mathrm{C}_{\text {fur }}$ is the furan concentration in the oil expressed in ppm. Finally 


$$
I_{2}(1)=0.3 \cdot \mathrm{HI}_{2}(\mathrm{C}, 0)+0.7 \cdot \mathrm{HI}_{2}(\text { fur })
$$

The second subindex $\mathrm{I}_{2}(2)$ is concerned with the concentrations of five gases dissolved in the oil, namely $\mathrm{H}_{2}, \mathrm{CH}_{4}, \mathrm{C}_{2} \mathrm{H}_{6}, \mathrm{C}_{2} \mathrm{H}_{4}$, and $\mathrm{C}_{2} \mathrm{H}_{2}$, and is given by

$$
I_{2}(2)=\sum_{j=1}^{5} w_{j} \cdot F_{\mathrm{j}}
$$

where the values of $F_{1}$ through $F_{5}$ are expressed in the form $a x+b$, where $x$ is the concentration of the relevant gas, as shown in Table 7.

\begin{tabular}{|c|c|c|c|c|}
\hline GAS & $\begin{array}{l}\text { Concentration } \\
\text { range } x(\mu L / L)\end{array}$ & a & b & $\mathbf{F}$ \\
\hline \multirow{5}{*}{$\mathrm{H}_{2}$} & $\leq 30$ & 0 & 0 & \multirow{4}{*}{$F_{1}=a x+b$} \\
\hline & $30-50$ & 0.1 & -3 & \\
\hline & $50-100$ & 0.06 & 1 & \\
\hline & $100-500$ & 0.0125 & 3.75 & \\
\hline & $>500$ & & & $F_{1}=10$ \\
\hline \multirow{4}{*}{$\mathrm{CH}_{4}$} & $\leq 10$ & 0 & 0 & \multirow{3}{*}{$F_{2}=a x+b$} \\
\hline & $10-15$ & 0.4 & -2 & \\
\hline & $15-125$ & 0.0727 & 0.9 & \\
\hline & $>125$ & & & $F_{2}=10$ \\
\hline \multirow{5}{*}{$\mathrm{C}_{2} \mathrm{H}_{6}$} & $\leq 5$ & 0 & 0 & \multirow{4}{*}{$F_{3}=a x+b$} \\
\hline & $5-20$ & 0.1333 & -0.6667 & \\
\hline & $20-35$ & 0.2 & -2 & \\
\hline & $35-70$ & 0.125 & 0.625 & \\
\hline & $>70$ & & & $F_{3}=10$ \\
\hline \multirow{5}{*}{$\mathrm{C}_{2} \mathrm{H}_{4}$} & $\leq 10$ & 0 & 0 & \multirow{4}{*}{$F_{4}=a x+b$} \\
\hline & $10-30$ & 0.1 & -1 & \\
\hline & $30-50$ & 0.15 & -2.5 & \\
\hline & $50-75$ & 0.04 & 3 & \\
\hline & $>175$ & & & $F_{4}=10$ \\
\hline \multirow{5}{*}{$\mathrm{C}_{2} \mathrm{H}_{2}$} & $\leq 0.5$ & 0 & 0 & \multirow{4}{*}{$F_{5}=a x+b$} \\
\hline & $0.5-3$ & 0.8 & -0.4 & \\
\hline & $3-5$ & 1.5 & -2.5 & \\
\hline & $5-35$ & 0.1667 & 4.167 & \\
\hline & $>35$ & & & $F_{5}=10$ \\
\hline
\end{tabular}

Table 7. Values of $F_{1}$ through $F_{5}$ (based on [8]).

The weights $\mathrm{w}_{\mathrm{j}}$ assigned to each gas are given in Table 8.

Table 8. Weight $\left(w_{j}\right)$ for each of the five dissolved gases (based on [8]).

\begin{tabular}{|c|c|}
\hline $\mathbf{G a s}$ & $\mathbf{w}_{\mathbf{j}}$ \\
\hline $\mathrm{H}_{2}$ & 0.2310 \\
\hline $\mathrm{CH}_{4}$ & 0.2306 \\
\hline $\mathrm{C}_{2} \mathrm{H}_{6}$ & 0.0772 \\
\hline $\mathrm{C}_{2} \mathrm{H}_{4}$ & 0.2301 \\
\hline $\mathrm{C}_{2} \mathrm{H}_{2}$ & 0.2312 \\
\hline
\end{tabular}

The third subindex $\mathrm{I}_{2}(3)$ is based on acid content of the oil (expressed as the mass of $\mathrm{KOH}$ required to neutralize $1 \mathrm{~g}$ of oil), its dielectric strength, moisture content and dielectric loss, as given in eq.(7).

$$
I_{2}(3)=\sum_{j=1}^{4} w_{j} \cdot F_{o i l(j)}
$$

Values of the four $F_{\text {oil }}$ factors are given in Tables 9-12, and the statistical weights in Table 13. 
Table 9. Values of $F_{\text {oil }}(1)$ (acid content of the oil) (based on [8]).

\begin{tabular}{|c|c|c|c|c|c|}
\hline \multicolumn{2}{|c|}{$\mathrm{U} \leq 69 \mathrm{kV}$} & \multicolumn{2}{|c|}{$69 \mathrm{kV}<\mathrm{U}<230 \mathrm{kV}$} & \multicolumn{2}{|c|}{$\mathrm{U}>230 \mathrm{kV}$} \\
\hline$x(\mathrm{mg} \mathrm{KOH} / \mathrm{g})$ & $F_{\text {oil }}(1)$ & $x(\mathrm{mg} \mathrm{KOH} / \mathrm{g})$ & $F_{\text {oil }}(1)$ & $\mathrm{x}(\mathrm{mg} \mathrm{KOH} / \mathrm{g})$ & $F_{\text {oil }}(1)$ \\
\hline$x \leq 0.015$ & 0 & $x \leq 0.015$ & 0 & $x \leq 0.015$ & 0 \\
\hline $0.015<x \leq 0.1$ & $25.53 . x-0.353$ & $0.015<x \leq 0.1$ & $25.53 . x-0.353$ & $0.015<x \leq 0.05$ & 51.14.x - 0.857 \\
\hline $0.1<x \leq 0.2$ & $20 . x$ & $0.1<x \leq 0.25$ & $40 . x-2$ & $0.05<x \leq 0.2$ & $40 . x$ \\
\hline $0.2<x \leq 0.3$ & $40 . x-4$ & $x>0.25$ & 10 & $x>0.2$ & 10 \\
\hline
\end{tabular}

Table 10. Values of $F_{\text {oil }}(2)$ (dielectric strength of the oil) (based on [8]).

\begin{tabular}{|c|c|c|c|c|c|}
\hline \multicolumn{2}{|c|}{$\mathrm{U} \leq 69 \mathrm{kV}$} & \multicolumn{2}{|c|}{$69 \mathrm{kV}<\mathrm{U}<230 \mathrm{kV}$} & \multicolumn{2}{|c|}{ U > 230 kV } \\
\hline$x(k V)^{*}$ & $F_{\text {oil }}(2)$ & $x(k V) *$ & $F_{\text {oil }}(2)$ & $x(k V) *$ & $F_{\text {oil }}(2)$ \\
\hline$x>45$ & 0 & $x>52$ & 0 & \multirow{2}{*}{$x>60$} & \multirow{2}{*}{0} \\
\hline $43<x \leq 45$ & $-x+45$ & $50<x \leq 52$ & $-x+52$ & & \\
\hline $40<x \leq 43$ & $0.667 . x+30.68$ & $47<x \leq 50$ & $0.667 . x+35.35$ & \multirow{2}{*}{$40<x \leq 60$} & \multirow{2}{*}{$-0.4 . x+24$} \\
\hline $30<x \leq 40$ & $-0.4 . x+20$ & $40<x \leq 47$ & $-0.286 . x+17.44$ & & \\
\hline$x \leq 30$ & 10 & $35<x \leq 40$ & $-0.4 . x+22$ & \multirow{2}{*}{$x \leq 40$} & \multirow{2}{*}{10} \\
\hline & & $x \leq 35$ & 10 & & \\
\hline
\end{tabular}

* Assuming an electrode separation of $2.5 \mathrm{~mm}$ (IEC 60156)

Table 11. Values of $F_{\text {oil }}(3)$ (moisture content of the oil) (based on [8]).

\begin{tabular}{|c|c|c|c|c|c|}
\hline \multicolumn{2}{|c|}{$\mathrm{U} \leq 69 \mathrm{kV}$} & \multicolumn{2}{|c|}{$69 \mathrm{kV}<\mathrm{U}<230 \mathrm{kV}$} & \multicolumn{2}{|c|}{$\mathrm{U} \geq 230 \mathrm{kV}$} \\
\hline$x(\mathrm{mg} / \mathrm{kg})$ & $F_{\text {oil }}(3)$ & $x(\mathrm{mg} / \mathrm{kg})$ & $F_{\text {oil }}(3)$ & $x(\mathrm{mg} / \mathrm{kg})$ & $F_{\text {oil }}(3)$ \\
\hline$x \leq 20$ & 0 & $x \leq 10$ & 0 & $x \leq 10$ & 0 \\
\hline $20<x \leq 30$ & $0.2 . x-4$ & $10<x \leq 20$ & $0.2 . x-2$ & $20<x \leq 30$ & $0.4 . x-4$ \\
\hline $30<x \leq 45$ & $0.4 . x-10$ & $20<x \leq 35$ & $0.4 . x-6$ & $x>30$ & 10 \\
\hline$x>45$ & 10 & $x>35$ & 10 & & \\
\hline
\end{tabular}

Table 12. Values of $F_{\text {oil }}(4)$ (dielectric loss of the oil) (based on [8]).

\begin{tabular}{|c|c|}
\hline $\tan \mathbf{\delta}$ & $\mathbf{F}_{\text {oil }}$ (4) \\
\hline $\mathrm{x} \leq 0.05$ & 0 \\
\hline $0.05<\mathrm{x} \leq 0.15$ & $20 . \mathrm{x}-1$ \\
\hline $0.15<\mathrm{x} \leq 0.5$ & $5.714 . \mathrm{x}+1.143$ \\
\hline $0.5<\mathrm{x} \leq 1.5$ & $4 . \mathrm{x}+2$ \\
\hline $\mathrm{x}>1.5$ & 10 \\
\hline
\end{tabular}

Table 13. Weight $\left(w_{j}\right)$ for each of the four factors $F_{\text {oil }}$ (based on [8]).

\begin{tabular}{|c|c|}
\hline Physical property & $\mathbf{w}_{\mathbf{j}}$ \\
\hline Acidity & 0.2598 \\
\hline Dielectric strength & 0.1452 \\
\hline Moisture & 0.4565 \\
\hline Loss factor & 0.1386 \\
\hline
\end{tabular}

The fourth subindex $\mathrm{I}_{2}(4)$ is concerned with the age and loading of the transformer, and is given by eq.(8),

$$
I_{2}(4)=H I_{2}(0) \cdot e^{B \cdot\left(t_{2}-t_{1}\right)}
$$

where $\mathrm{HI}_{2}(0)$ is an initial factor, $\mathrm{B}$ is an aging coefficient, $\mathrm{t}_{1}$ is the year in which $\mathrm{HI}_{2}(0)$ was evaluated, and $t_{2}$ is the year in which the state of the transformer is now being evaluated. $\mathrm{HI}_{2}(0)$ is related to the condition of the transformer when it entered service, and its value is usually 0.5 , whereas it is about 6.5 when the transformer reaches the end of its service lifetime. Given that the expected service lifetime of the transformers involved in this study is 40 years, when operating below $40 \%$ of rated load, as quoted by the manufacturers, it follows that $B=(\ln (13)) / 40=0.064$ year $^{-1}$ under such loading. However, the expected service lifetime decreases with increasing loading of the transformer, and therefore at higher percentage loadings $B$ is increased by a load factor fload, as given in Table 14. 
Table 14. Values of load factor $f_{\text {load }}$ (based on [8]).

\begin{tabular}{|c|c|}
\hline $\begin{array}{c}\text { Loading } \\
(\mathbf{\%})\end{array}$ & $\begin{array}{c}\text { Load factor } \\
\mathbf{f}_{\text {load }}\end{array}$ \\
\hline $0-40$ & 1 \\
\hline $40-60$ & 1.05 \\
\hline $60-70$ & 1.1 \\
\hline $70-80$ & 1.25 \\
\hline $80-150$ & 1.6 \\
\hline
\end{tabular}

The overall health index $\mathrm{I}_{2}$ is given by

$$
I_{2}=\sum_{i=1}^{4} k_{i} \cdot I_{2}(i)
$$

where the weights $\mathrm{k}_{1}$ (state of the insulating paper), $\mathrm{k}_{2}$ (concentrations of five dissolved gases in the oil), $\mathrm{k}_{3}$ (acid content of the oil) and $\mathrm{k}_{4}$ (age and loading of the transformer) are $0.2661,0.0946,0.0699$ and 0.5695 respectively. $\mathrm{I}_{2}$ lies in the range $0-10$. The overall condition of the transformer, based on the value of $I_{2}$, is listed in Table 15.

Table 15. Transformer condition as a function of the health index $I_{2}$ (based on [8]).

\begin{tabular}{|c|c|}
\hline $\mathbf{I}_{2}$ & Condition \\
\hline $0-3.5$ & Very good \\
\hline $3.5-5.5$ & Good \\
\hline $5.5-7$ & Bad \\
\hline $7-10$ & Very bad \\
\hline
\end{tabular}

\subsection{Comparison of $I_{1}$ and $I_{2}$ for 52 transformers}

Figure 1 shows the indexes $I_{1}$ and $I_{2}$ for each of the 52 transformers, evaluated annually from 2011 to 2015 . The transformers have been grouped according to their average time-in-service, i.e., 10 transformers with average time-in-service of 10 years, 10 transformers with 20 years, 10 transformers with 30 years, 10 transformers with 40 years, and 12 transformers with 50 years.

It will be seen that the minimum value of $I_{1}$, for the twelve transformers with average time-in-service of 50 years, was 0.2 over the five year period, and the maximum value was around 0.9 . The corresponding minimum and maximum values for the ten transformers with average time-in-service of 10 years were 0.35 and 0.9 respectively. These unexpectedly large variations within a transformer group almost certainly occurred because some parameters used to estimate $I_{1}$ varied considerably with time, e.g., the concentrations of moisture, $\mathrm{CO}, \mathrm{CO}_{2}$ and $2 \mathrm{FAL}$, as a result of variations in the environments in which these parameters were measured. In climates with high atmospheric moisture content, collection of oil samples must be carried out very carefully, in order to avoid contamination. Consequently the observed variation 
of $I_{1}$ almost certainly does not accurately reflect the true state of the solid insulation of the transformers, which is expected to age monotonically with time in service.

On the other hand, $I_{2}$ tends to increase gradually for each transformer within the same two groups, as expected. The values for the 50 year transformers range from around 5 in 2011 to around 8 in 2015, the corresponding range for the 10 year transformers being 1-2.

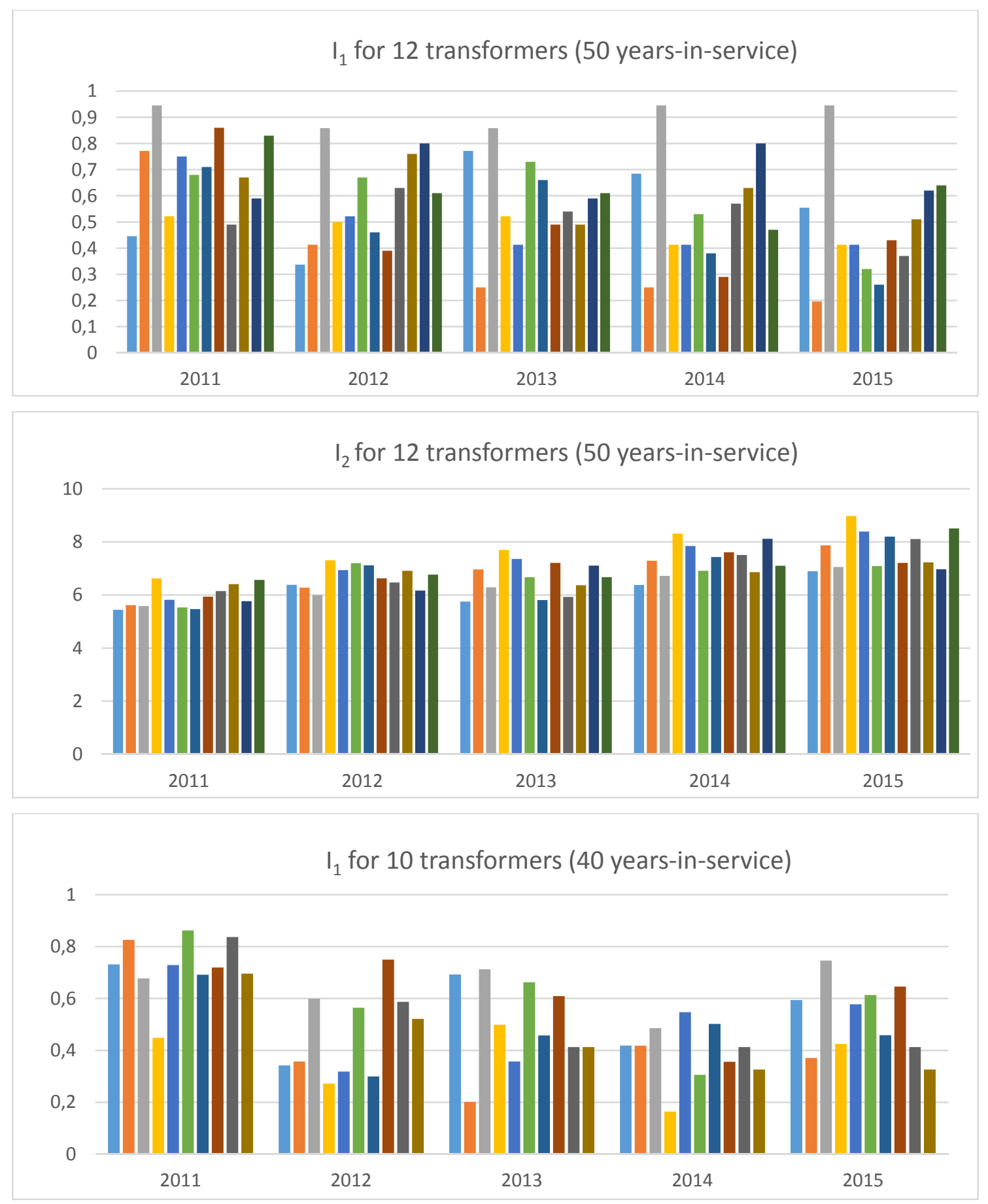



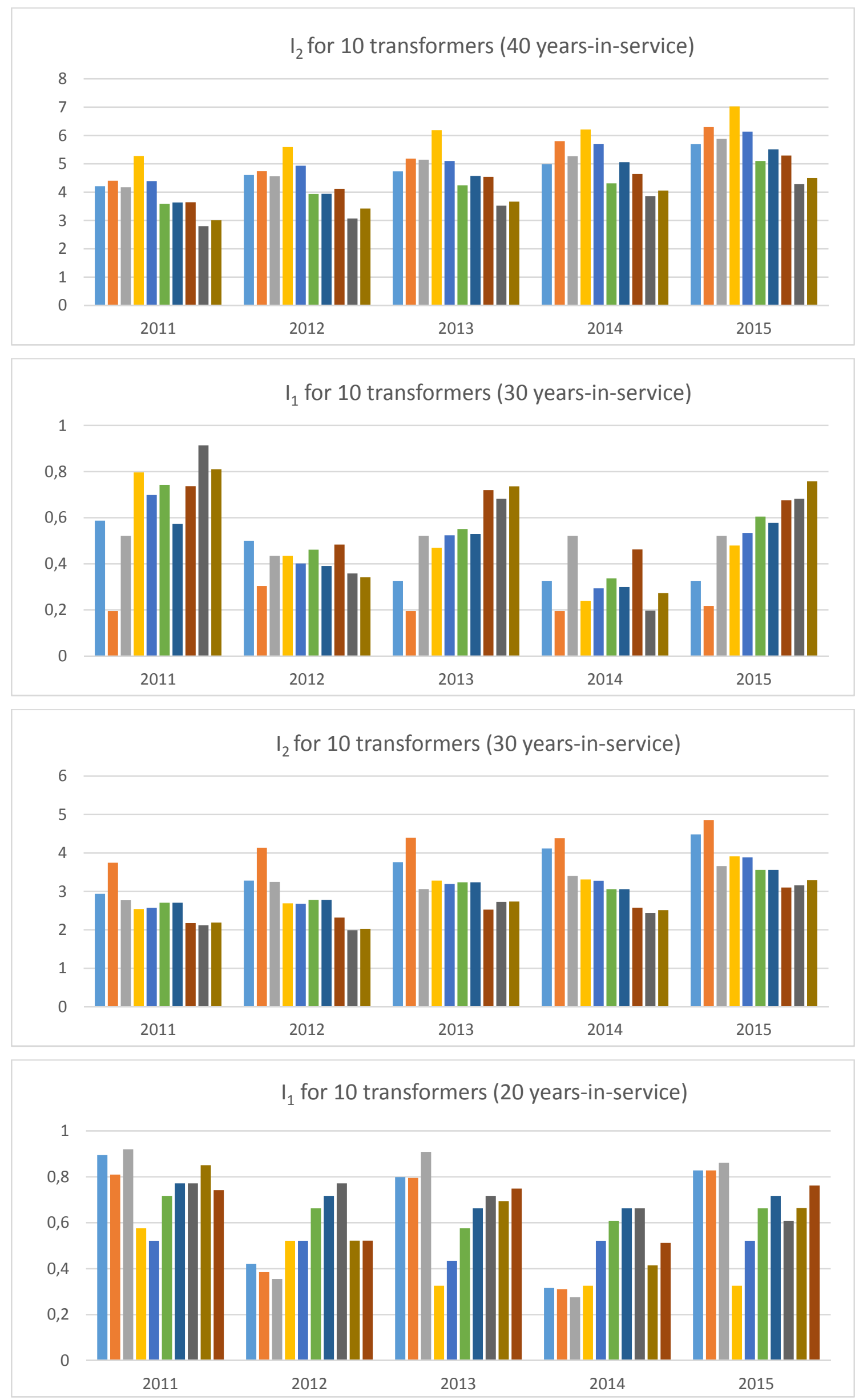

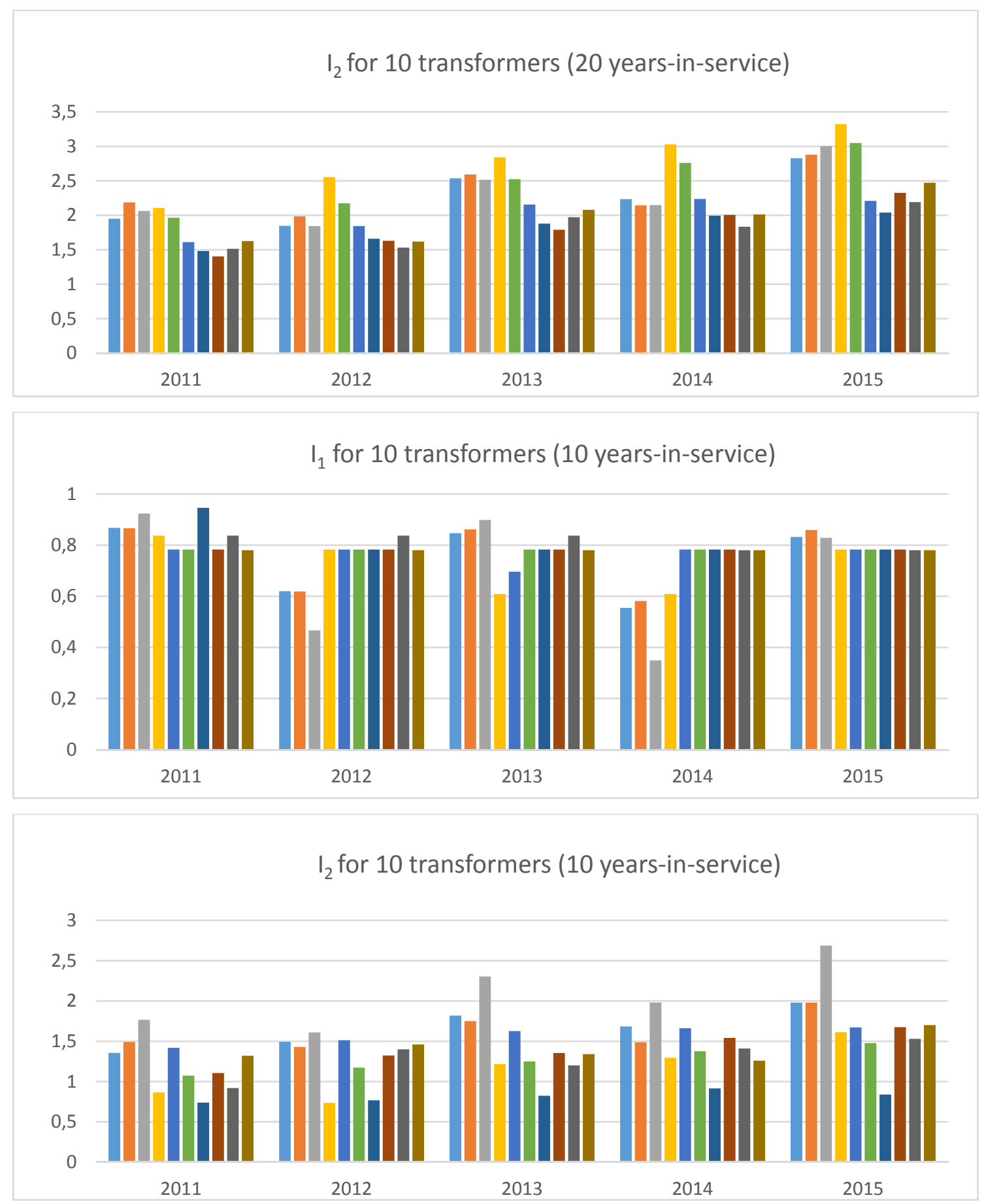

Figure 1. $I_{1}$ and $I_{2}$ for transformers in five years-in-service groups, evaluated over the last five years. 


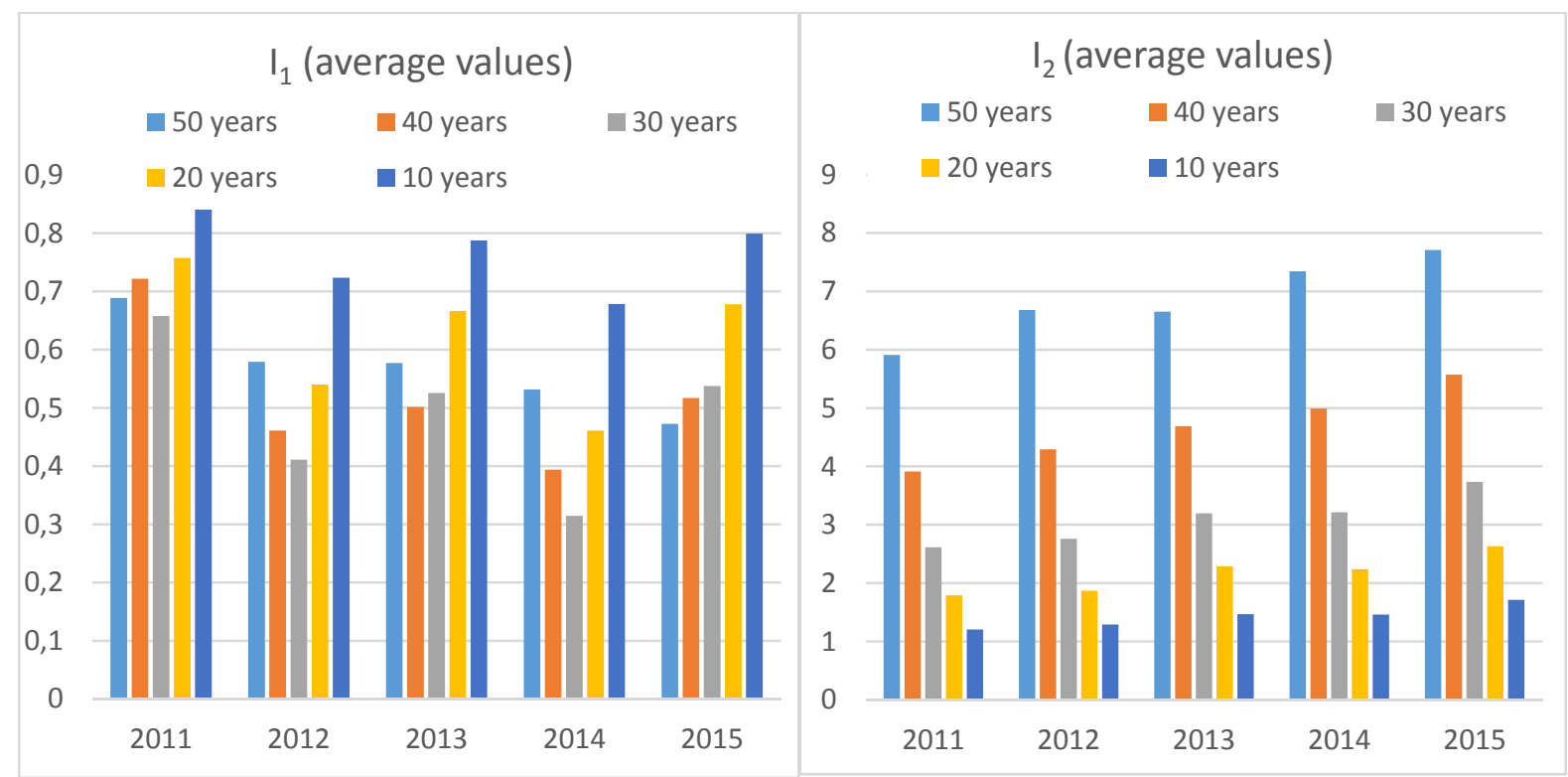

Figure 2. Values of $I_{1}$ and $I_{2}$ averaged within each of the five years-in-service groups, over the last five years.

Figure 2 shows the average values of $\mathrm{I}_{1}$ and $\mathrm{I}_{2}$ for the five groups of transformers with average times-in-service of $10,20,30,40$ and 50 years. The average values of $I_{2}$ show the same ordering between groups in each of the five years, while the average values of $I_{1}$ vary in an almost random fashion.

The following aspects of the data presented in Figures 1 and 2 should be noted:

- The average values of $I_{1}$ and $I_{2}$ both show that, in each of the five measurement years, the 10 year group of transformers is in better condition than each of the other groups, as would be expected. $I_{2}$ consistently shows that the younger the transformers the better their condition, as would be expected. The same is not true of $I_{1}$.

- A marked decrease in $\mathrm{I}_{1}$ between two consecutive measurements could indicate the presence of a fault. On the other hand, a marked increase could be due to regeneration or replacement of the oil. A clear example of the latter can be observed for the first transformer (light blue colour) in the 50 year group, in which the oil was regenerated in 2012. I increase markedly in 2013, and then decreases in 2014 and 2015. I2 shows the opposite effect, as would be expected, but to a much lesser extent.

- The index $I_{2}$ is probably a more reliable indicator of overall transformer health than the index $I_{1}$. The main reason seems to be that $I_{2}$ takes into account the time for which a transformer has been in service and the extent to which it has been loaded; $I_{1}$ does not do so. The remaining service lifetime of a transformer is determined mainly by the condition of its paper insulation, which usually deteriorates gradually with time.

- Collection of uncontaminated oil samples for analysis is essential if the health index $I_{1}$ is to be accurately evaluated. However, it seems unlikely that more careful sample collection would render $\mathrm{I}_{1}$ more reliable than $\mathrm{I}_{2}$.

\section{Conclusions}

We conclude that health index $\mathrm{I}_{2}$ is a more reliable indicator of transformer overall health than health index $I_{1}$. Although both make use of the same physical data, e.g., acid content of the oil, dissolved gas content of the oil, breakdown voltage and 
dielectric loss, only $\mathrm{I}_{2}$ takes into account the time for which a transformer has been in service and the extent to which it has been loaded. The latter two factors seem to be essential to ensure that the health index reflects the expected monotonic deterioration in the condition of the transformer insulation with time in service. However, health index $I_{1}$ is probably a clearer indicator of a significant change in overall transformer health since the last measurement.

\section{Acknowledgments}

The authors gratefully acknowledge funding of this work from several sources, particularly support in the later stages from the Spanish Plan Estatal de I+D under the grant agreement DPI2013-43897-P.

\section{REFERENCES}

[1] J. Haema, R. Phadungthin, "Development of Condition Evaluation for Power Transformer Maintenance," Int. Conf. on Power Eng., Energy and Electr. Drives, pp. 620-623, 2013.

[2] A. N. Jahromi, R. Piercy, S. Cress, J. Service, W. Fan, "An Approach to Power Transformer Asset Management Using Health Index," IEEE Electr. Insul. Mag., vol. 25, no. 2, pp. 20-34, 2009.

[3] M.K. Pradhan, T.S. Ramu, "On the Estimation of Elapsed Life of Oil-Immersed Power Transformers". IEEE Trans. Power Del. vol. 20, no. 3, pp. 1962-1969, 2005.

[4] K. Taengko, "Risk assessment for power transformers in PEA substations using health index," Int. Conf. on Elect. Eng./Electron. Comput. Telecommun. and Inform. Technol. pp. 16, 2013.

[5] A. Naderian, "An Approach to Determine the Health Index of Power Transformers," IEEE Int. Symp. on Elect. Insul. pp. 192 - 196, 2008.

[6] J. Haema, "Condition assessment of the health index for power transformer," IEEE Power Eng. and Automat. Conf.pp. 1 - 4, 2012.

[7] I. G. N. Satriyadi Hernanda, A. C. Mulyana, D. A. Asfani, I. M. Y. Negara, D. Fahmi, "Application of Health Index Method for Transformer Condition Assessment," IEEE TENCON Region 10 Conf., pp. 1-6, 2014.

[8] E. Li, B. Song, "Transformer Health Status Evaluation Model Based on Multi-feature Factors," Int. Conf. on Power Syst. Technol., pp. 1417-1422, 2014.

\section{BIOGRAPHIES}

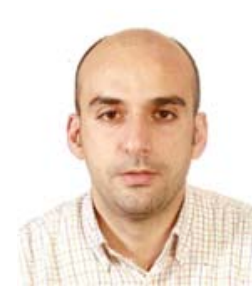

Félix Ortiz received the M.Sc. degree in physical sciences in 2000 from the University of Cantabria (UC), Spain, and is currently pursuing the Ph.D. degree. He is Aggregate Professor of Electrical and Energy Engineering Department, UC. He has presented more than 10 papers at international conferences, and has published one journal paper. His main research topic is currently alternative dielectric liquids for power transformers.

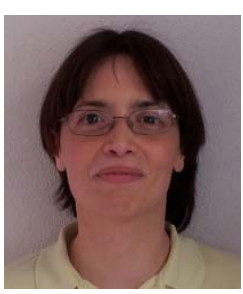

Inmaculada Fernández received the M.Sc. degree in chemical engineering in 2004 and the Ph.D. degree in 2009 from the University of Cantabria (UC), Spain. She is Assistant Professor in the Electrical and Energy Engineering Department, UC. She has published two chapters in international books and 12 journal papers, 
and has presented more than 20 papers at national and international conferences. Her main research topic is energy saving.

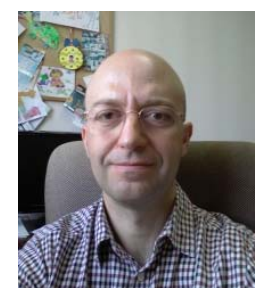

Alfredo Ortiz received the M.Sc. degree in industrial engineering in 1997, and the Ph.D. degree in 2005, from the University of Cantabria (UC), Spain. He is Associate Professor and Head of the Electrical and Energy Engineering Department, UC. He has published six chapters in international books, and 26 journal papers, and has presented more than 50 papers works at international conferences. His main research topic is alternative dielectric liquids in power transformers.

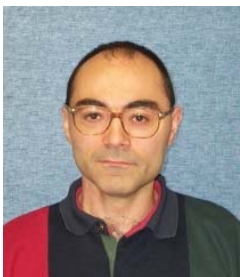

Carlos J. Renedo received the M.Sc. degree in industrial engineering in 1997, and the Ph.D. degree in 2002, from the University of Cantabria (UC), Spain. He is Associate Professor in the Electrical and Energy Engineering Department, UC, and Vicedean of the School of Industrial Engineering and Telecommunications. He has presented more than 50 papers at international conferences, and published 24 journal papers. His main research topic is energy saving.

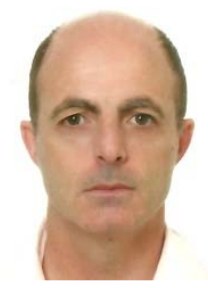

Fernando Delgado received the M.Sc. degree in industrial engineering in 1998, and the Ph.D. degree in 2011, from the University of Cantabria (UC), Spain. He is Associate Professor in the Electrical and Energy Engineering Department, UC. He has presented more than 25 papers works at international conferences, and published 13 journal papers His main research topic is alternative dielectric liquids for power transformers.

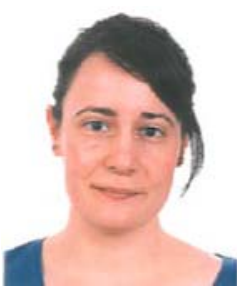

Cristina Fernández received the B.Sc. degree in civil engineering in 2014 from the University of Cantabria (UC), Spain, and is now pursuing an M.Sc. degree She has presented 3 papers at conferences. Her main research topic is power transformer insulation systems. 